\title{
Cystic Fibrosis - An Update
}

\author{
MOHAMMED RIZWANULAHSAN ${ }^{1}$, HOSSAIN SHAHID KAMRULALAM ${ }^{2}$, AHMED RASHEDUL HASAN ${ }^{3}$, \\ MIRZAZIAUL ISLAM ${ }^{4}$, AHMED HOSSAIN $^{5}$
}

\begin{abstract}
Cystic fibrosis (CF) is said to be the most common lethal inherited disease of the white population. It affects the exocrine glands of body, primarily of the gastrointestinal and respiratory system. CF is caused by one of a large numbers of mutations of the gene for a protein called the cystic fibrosis transmembrane conductance regulator (CFTR). This CFTR regulates chloride and sodium transport across epithelial membranes. The main complications involve in the lungs, with damage to the small and large airways by chronic and recurrent bacterial infections. Other major consequences include pancreatic malfunction, leading to malabsorption of nutrients and vitamins with consequent impaired growth and development and in older patient diabetes. Diagnosis is usually done by sweat test or identification of two CF-causing mutations in patients with characteristics symptoms. Treatment is supportive through aggressive multidisciplinary care. The prognosis of CF has improved due to earlier diagnosis through screening, better treatment and access to health care. Although CF is a rare disease in Bangladesh, but its possibility should be kept in mind in appropriate circumstances.
\end{abstract}

Key words: Cystic fibrosis, inherited disease, cystic fibrosis transmembrane conductance regulator (CFTR), Sweat test

\section{Introduction}

"The child who tastes salty will soon die" - German folklore. A series of events that took place during the very hot summer of 1938 in New York City led to the recognition of a new disease, Cystic fibrosis (CF). Dr. Dorothea Anderson ${ }^{1}$ noted that a number of children presented to Columbia Hospital with severe dehydration, but without diarrhea or vomiting. Several of these children had been followed in the gastrointestinal clinic for failure to thrive and greasy stool, many also had coughed. Thus began the recognition of Cystic fibrosis (CF) of the pancreas. By 1946, the genetic nature of this autosomal recessive disorder was described. In 1953, Dr. Paul di Sant' Agnese recognized that $C F$ patients lost excessive salt in their sweat, ${ }^{2}$ forming the basis for use of the sweat chloride test as a cornerstone of the diagnosis of the disease.

1. Resident Physician, Dhaka Shishu (Children) Hospital, Dhaka.

2. Asstistant Professor, Department of Adolescent Pediatric Unit, Dhaka Shishu (Children) Hospital.

3. Medical Officer, Dhaka Shishu (Children) Hospital.

4. Assist Professor, Dhaka Shishu (Children) Hospital.

5. Medical Officer, Dhaka Shishu (Children) Hospital.

Correspondence: Dr. Mohammed Rizwanul Ahsan, Resident Physician, Dhaka Shishu (Children) Hospital, Dhaka. E-mail: rizwanul.ahsan@gmail.com
Cystic fibrosis (CF), also known as mucovisidosis, is a genetic disorder that affects mostly the lungs but also the pancreas, liver, kidney, intestines. It is an autosomal recessive disorder caused by the presence of mutations in both copies of the gene for the protein cystic fibrosis transmembrane conductance regulator (CFTR). ${ }^{3}$ Those with single working copy are carriers and otherwise mostly normal. ${ }^{4}$ CFTR is involved in production of sweat, digestive fluids and mucus. ${ }^{5}$ When CFTR is not functional, secretions which are usually thin instead become thick. ${ }^{6}$ This condition is diagnosed by sweat test and genetic testing. Screening at birth takes places in some areas of the world. There is no cure for CF. Lung infections are treated with antibiotics which may be given intravenously, inhaled or by mouth. Inhaled hypertonic saline and salbutamol may also be useful. Pancreatic enzyme replacement and soluble vitamin supplementation are important especially in the young. Many people use airway clearance technique such as chest physiotherapy. ${ }^{3}$ The average life expectancy is between 37 to 50 years in the developed world. ${ }^{7}$ Lung problems are responsible for death in $80 \%$ of people with CF. 


\section{Epidemiology}

Cystic fibrosis is the most common life- limiting autosomal recessive disorder among people of European heritage. ${ }^{8}$ In the United States (US), approximately 30,000 individuals have CF; most are diagnosed by six months of age. Approximately 1 in 25 people of European descent, and 1 in 30 of Caucasian American, are a carrier of CF mutation. ${ }^{9}$ Although CF is less common in these groups, approximately 1 in 46 Hispanics, 1 in 65 Africans and 1 in 90 Asian carry at least one abnormal cystic fibrosis transmembrane conductance regulator (CFTR) gene. ${ }^{10}$ Ireland has the world's highest prevalence of CF at 1:1353. ${ }^{11}$ World Health Organization (WHO) states that "In the European Union, 1 in 2000-3000 newborn is found to be affected by CF". ${ }^{12}$ In the US, 1 in 3500 children is born with CF. ${ }^{13}$ CF is diagnosed in both males and females equally.

\section{Etiology/genetics}

Typically, CF is caused by two lesions in the CFTR gene, which gives rise to a generalized exocrine disease of the respiratory, gastrointestinal, reproductive, hepato-biliary tract. ${ }^{15}$ The $\mathrm{CF}$ mutations have been localized to chromosome 7 , band q31. ${ }^{16,17}$ the locus codes for a transport protein named the CFTR. ${ }^{18}$ More than 800 mutations are now found. The Caucasian associated delta F508 defect is the most common mutation found. The genetic variations and molecular implications are becoming clearer. ${ }^{19}$ The protein product of the cystic fibrosis transmembrane conductance regulator (CFTR) gene is a chloride channel expressed in the apical membrane of epithelial cells. ${ }^{20}$

\section{Pathophysiology}

The name Cystic fibrosis (CF) refers to the characteristic fibrosis and cysts that form within the pancrease ${ }^{1}$. There are several mutations in the CFTR gene; the different mutations cause different defects in the CFTR protein, sometimes causing a milder or more severe disease. The CFTR protein is anchored to the outer membrane of cells in the sweat glands, lungs, pancreas and all other remaining exocrine gland of the body and acts as a channel connecting the inner part of the cells (cytoplasm) to the surrounding fluid. The channel is primarily responsible for controlling the movement of halogens from inside to the outside of the cells; however, in the sweat ducts, it facilitates the movement of chloride from the sweat duct into cytoplasm. When the CFTR protein does not resorb ions in sweat ducts, chloride and thiocynate inside the ducts and pumped into the skin. Because chloride is negatively charged, this creates a difference in the electrical potential inside and outside the cells causing catpoms to cross into the cell. The excess chloride within the sweat ducts prevents sodium desorption by epithelial sodium channels and the combination of sodium and chloride creates the salt, which is lost in high amounts in the sweats of several of individuals with CF. This lost salt forms the basis for the sweat tests. ${ }^{20}$

\section{Clinical manifestations}

The main signs and symptoms of CF are salt testing skin, ${ }^{21}$ poor growths and poor weight gain despite normal food intake, ${ }^{22}$ accumulation of thick, sticky mucus ${ }^{23}$, frequent chest infections and coughing or shortness of breath. ${ }^{24}$ In a review of CF patients, the frequency of presenting signs and symptoms were: acute or persistent respiratory illness $(51 \%)$, failure to thrive or malnutrition (43\%), abnormal stool or steatorrhoea $(35 \%)$, meconium ileus or intestinal obstruction (19\%), family history of CF $(17 \%)$, electrolyte imbalance $(5 \%)$, hepatobiliary disease $(91 \%)$ and prenatal diagnosis by chorionic villus sampling or amniocentesis (1\%). signs and symptoms often appear in infancy and childhood, such as bowel obstruction due to meconium ileus in newborn babies. ${ }^{26}$ The poor growth in children typically presents as an inability to gain weight or height at the same rate as their peers. The causes of growth failure are multifactorial and include chronic illness. ${ }^{27}$

\section{Diagnosis}

Cystic fibrosis (CF) may be diagnosed by many different methods which include followings ${ }^{28}$ :

- Universal newborn screening

- May also be suggested by a positive prenatal screening test result, family history or symptomatic presentation.

- Confirmed by a sweat test showing elevated sweat chloride on two or more occasions

- Can be confirmed by identifying $2 \mathrm{CF}$ - causing mutation (1 on each chromosome)

- May rarely be confirmed, in atypical cases, by demonstrating abnormal ion transport across epithelium.

As of 2006, in the United States, 10 percent of cases are diagnosed shortly after birth as part of newborn 
screening programs. The newborn screening initially measures for raised concentration of immunoreactive trypsinogen ${ }^{29}$. Infants with an abnormal newborn screen need a sweat test to confirm the CF diagnosis. ${ }^{37}$ Couples who are pregnant or planning a pregnancy can have themselves tested for the CFTR mutations to determine the risk that their child will be born with CF. Testing is typically performed first on one or both partners and, if the risk is high, testing on the fetus is performed. Testing analyzes the blood for the most commom mutations such as AF 508-most commercially available tests look for 32 or fever different mutations. ${ }^{30}$ During pregnancy, testing can be performed by chorionic villus sampling or aminocentesis. ${ }^{31}$ However, Most individuals are diagnosed after symptoms (e.g. sinpulmonary disease and gastrointestinal manifestations) prompt an evaluation for cystic fibrosis. Despite advances in genetic testing, the sweat chloride test remains the standard for confirming a cystic fibrosis diagnosis in most cases because of its sensitivity and specificity, simplicity and availability. ${ }^{32}$

\section{Management}

While there are no cures for CF, comprehensive and intensive therapy should be directed by an experienced physician working with a multidisciplinary team that includes other than physicians, nurses, dieticians, physical and respiratory therapists, counselors, pharmacists and social workers. The goal of therapy are maintenance of nutritional status, prevention or aggressive treatment of pulmonary and other complications, encouragement of physical activity and provision of psychological support. ${ }^{29}$ The most consistent aspect of therapy in CF is limiting and treating the lung damage caused by thick mucus and infection, with the goal of maintaining quality of life. Intravenous, inhaled and oral antibiotics are used to treat chronic and acute infections. Mechanical devices and inhalation medications are used to alter and clear the thickened mucus. Many patients with $\mathrm{CF}$ are on one or more antibiotics at all times, even when healthy, to prophylactically suppress infection. ${ }^{33}$ Several mechanical techniques are used to dislodge sputum and encourage its expectoration. In the hospital setting, chest physiotherapy (CPT) is utilized; a respiratory therapist percusses an individual's chest with hands several times a day to lossen up secretions. Devices that recreate this percussive therapy include the THAIRapy Vest and the intrapulmonary percussive ventilator (IPV). ${ }^{34}$ Treatment of pancreatic insufficiency by replacement of missing digestive enzymes allows the duodenum to properly absorb nutrients and vitamins that would otherwise be lost in the feces. ${ }^{35}$ Poor growth may be avoided by insertion of a feeding tube for increasing calories through supplemental feeds or by administration of injected growth hormone. ${ }^{36}$ Development of osteoporosis can be prevented by increasing intake of vitamin $D$ and calcium and can be treated by biphosphonates. ${ }^{37}$ Females infertility may be overcome by assisted reproduction techniques. Male infertility caused by absence of the vas deferens may be overcome with testicular sperm extraction (TESE), collecting sperm cells directly from the testicles. ${ }^{38}$

\section{Research on potential cure}

Gene therapy has been explored as a potential cure for CF. Ideally, gene therapy places a copy of CFTR gene into the affected cells. Transferring the normal CFTR gene into the affected epithelial cells would result in the production of functional CFTR in all target cells without adverse reactions or inflammatory responses. Studies have shown that to prevent the lung manifestations of CF, only $5-10 \%$ normal amount of CFTR gene expression is needed. ${ }^{39}$ Multiple approaches have been tested for gene transfer, such as liposomes and viral vectors in animal models and clinical trials. However both methods were found to be relatively inefficient treatment options. ${ }^{31}$ There has been functional repair in culture of CFTR by CRISPR I Cas 9 in intestinal stem cell or gonads of CF patients. ${ }^{31}$ A number of small molecules that aim at compensating various mutations of the CFTR gene are under development. ${ }^{40}$

\section{Prognosis}

Epidemiological data demonstrates a dramatic improvement in survival for patients with CF over the last few decades, and projections suggest that trend will continue. Currently, the average CF patients may expect to 30.6 years. Considerable progress has been made in identifying treatments that delay the progression of pulmonary disease in CF. This promotes an acceptable quality of life for such patients. Typically those patients who do well are those maintained on individualized therapeutic regimens which include airway clearance therapy, appropriate antibiotics, the use of effective mucolytics and bronchodilators, anti-inflammatory therapy and well monitored nutritional support. ${ }^{41}$ 


\section{Conclusions}

Cystic fibrosis (CF) is one of the commonest lifelimiting inherited diseases among white populations specially in Caucasians. In most countries in Europe, USA, and South America, CF services are well developed and the survival of CF patients has improved significantly. Unfortunately there are no organized data based services of CF in Bangladesh till now. This is because of limited knowledge of CF due to its rarity and lack of broad based research. To identify most, if not all, CF patients in Bangladesh and to provide them appropriate care, there is a need to spread awareness about this illness amongst doctors and society. Increased knowledge will help establish diagnostic and clinical care services in different paths of Bangladesh as early diagnosis and appropriate treatment is the key to improve survival and quality of life of CF patients.

\section{References}

1. Anderson DH. Cystic Fibrosis of the pancreas and its relation to celiac disease, a clinical and pathological study. Am J Dis Child. 1938;56:34499.

2. Di Sant's Agnese PA, Darling RC, Perera GA, et al. Abnormal electrolyte composition of sweat in Cystic fibrosis of the pancreas. Pediatrics. 1953;12-549.

3. O' Sullivan BP, Freedman SD. "Cystic fibrosis". Lancet. 2009; 373 (9678); 1891-904.

4. Massie J, Delatycki MD. Cystic fibrosis carrier screening. Paediatric respiratory review. 2013; 14: 270-75.

5. Buckingham Le. Molecular diagnostic fundamentals, methods, and Clinical implications, $2^{\text {nd }}$ edt. Philadelphia: FADavis Co. p.351. ISBN 9780803629752.

6. Yankaskas JR, Marshall BC, Sufan B. Cystic fibrosis adult care consensus conference report. Chest. 2004; 125 (900100): 1-39.

7. Davies JC, Edmon AM, Orchard C. Recent advances in the management of Cystic fibrosis. Achieves of diseases in childhood. 2014;99: 1033-1036.

8. Tobias, Edward. Essential Medical Genetics. John Wiley and Sons, 2011. P312.

9. Genetic carrier testing. Cystic fibrosis foundation. 2007.
10. Rosenstein BJ, Cutting GR. The diagnosis of Cystic fibrosis:an onsensus Panel. J Pediatr. 1998; 132: 589-95.

11. Farrell P, Joffe S, Foley L, et al. Diagnosis of Cystic fibrosis in the Republic of Ireland: epidemiology and costs. Ir Med J. 2007; 100: 557-60.

12. WHO genes and human disease. Woo. Int. 201012-07. Retrieved. 2013-01-23.

13. Russell, Peter. Biology: The dynamic science, 2011. Belmont, CA: Brookscole, Cngage learning

14. Rosenfeld M, Davis R, Pep M, et al. Gender gap in Cystic fibrosis mortality. Am J Epidemiol. 1997; 145: 794-803.

15. Welsh MJ, Tsui LC, Boat TF. Cystic Fibrosis. In: Seriver CR, Bendet AL, Sly WS, Valle D, eds. The metabolic and molecular basis of inherited disease. Newyork: MCGraw Hil. 1995; 3799-76.

16. Tsui L-C, Buchwald M, Barker D. Cystic fibrosis locus defined by a genetically linked polymorphic DNA marker, Science. 1985;230-1054.

17. Riordan JR, Rommen JM, Buchanan D. Identification of Cystic fibrosis gene: Cloning and characterizations of complimentary DNA. Science. 1989; 245-1066.

18. Hasagawa HW, Skach W, Baker O. A multifunctional aqueous channel formed by CFTR. Science. 1992;258-1477.

19. Tsui L-C. the spectrum of Cystic fibrosis mutations. Trends genet. 1992; 8- 392.

20. Rowe SM, Miler S, Sorcher EJ. "Cystic fibrosis". The New England Journal of Medicine. 2005; 352:1992-2001.

21. Quinton PM. Cystic fibrosis: lessons from the sweat gland. Physiology (Bethesda). 2007;22:212-25.

22. Hardin DS. GH improves growth and clinical status in children with cystic fibrosis-a review of published studies. Eur J Endocrinol. 2004; 151 (suppl 1): 81-5.

23. De Lisle RC. Pass the bicarb: the importance of HCO3- for mucin release. J Clin Invest. 2009; 119:2535-7. 
24. O' Malley CA. Infection control in cystic fibrosis: cohorting, cross-contamination, and the respiratory therapist. Repair care. 2009; 54: 641-57.

25. Rosenstein BJ. What is a cystic fibrosis diagnosis? Clin Chest Med 1998; 19:423-41.

26. Blackman SM, DeeringBBsc R, MC Williams $\mathrm{R}$, et al. Relative contribution of genetic and nongenetic modifiers to intestinal obstruction in cystic fibrosis. Gastroenterology. 2006; 131: 1630-9

27. Reaves J, Wallance G. Unexplained bruishing, weighting the pros and cons of possible causes. Consultant for Pediatricians. 2010;9: 201-2.

28. Mishra A, Greaves R, Massie J. The relevance of sweat testing for the diagnosis of cystic fibrosis in the genomic era. The Clinical Biochemist Reviews/Australian Association of Clinical Biochemists. 2005; 26: 135-53.

29. 51.Davies JC, Alton E W, Bush A. Cystic Fibrosi. BMJ. 2007;335(7632):1255-59.

30. Elias S, Annas G.J, Simpson JL. Carrier screening for cystic fibrosis: implications for obstetric and gynaecologic practice, Am J Obstet Gyanecol. 1991; 154:1077-83.

31. Tabor A, Philip J, Madsen M. Randomised controlled trial of genetic amniocentesis in 4606 low risk women. Lancet. 1986; 1(8493):1287-93.

32. Stern RC. The diagnosis of cystic fibrosis. N Eng J Med. 1997; 336:487-91.

33. Wesrnman EM, Le Brun PP, Touw DS. Effect of nebulized colistin sulphate and colistin sulphomethate on lung function in patients with cystic fibrosis: a Pilot Study. J Cyst Fibrosis. 2004;3:23-28.

34. Vander Schans C, Prasad A, Main E, Van Der Schans Cees $P$, ed, "Chest physiotherapy compared to no chest physiotherapy for cystic fibrosis. Cochrane database of systematic reviews. 2000;2.

35. Somaraju UR, Sous-Moya A. Pancreatic enzyme replacement therapy for people with cystic fibrosis. The Cochrane database of systematic reviews. 2014;10.

36. Hardin DS, Rice J. Ahn C, et al. Growth hormone treatment enhances nutrition and growth in children with cystic fibrosis receiving entreral nutrition. J Pediatr. 2005;146:324-28.

37. Conwell LS, Chang AB, Louise S, ed. Biphophoante for osteoporosis in people with cystic fibrosis. Cochrane database Syst Rev. 2012;4.

38. Philipson GT, bpetrucco OM, Mathews CD. Congenital bilateral absence of the vas deferens, cystic fibrosis mutation analysis and intracytoplasmic spern injection. Hom Reprod. 2000;15:431-35.

39. Schwank G, Koo BK, Sasselli V, et al. Functional repair of CFTR by CRISPR/cas 9 in intestinal stem cell organoids of Cystic fibrosis patients. Cell stem cell. 2013; 13:653-58.

40. Dierz HC, New therapeutic approaches to Mandelian disorder. N Engl J Med. 2010; 363: 852-63.

41. Tale S, Elborn S. Progress towards gene therapy for Cystic fibrosis. Expert Opin Deliv 2005;2: 269-80. 